\title{
Frequency Distribution of Trichomoniasis in Pregnant Women in Aba, South East, Nigeria
}

\author{
Kanu Anulika Mercy ${ }^{1, *}$, Ihekwumere Ijeoma ${ }^{2}$, Kalu Emmanuel Jonah ${ }^{1}$ \\ ${ }^{1}$ Department of Biology/Microbiology, Abia State Polytechnic, Nigeria \\ ${ }^{2}$ Department of Microbiology, Abia State University, Nigeria
}

Copyright $(\mathcal{C} 2015$ by authors, all rights reserved. Authors agree that this article remains permanently open access under the terms of the Creative Commons Attribution License 4.0 International License

\begin{abstract}
A study of Trichomonas vaginalis infection among 200 pregnant women attending antenatal clinics in three different public and private health facilities in Aba was carried out between August to October, 2014. High Vaginal Swabs (HVS) were randomly collected from each of the subjects and samples were analyzed using microscopy method. The presence of Trichomonas vaginalis was detected by its characteristic jerking movement in a wet preparation. Of the 200 pregnant women studied, $26(13 \%)$ of the women were infected with $T$. vaginalis. Women within the age of $19-26$ years had the highest prevalence rate of $17.95 \%$ followed by those within age group $27-34$ years $(10.64 \%)$. However, the differences were not significant $\left(\mathrm{X}_{2}=3.002, \mathrm{P}>0.05\right)$. Women in the third trimester had the highest prevalence of $T$. vaginalis infection $(14.8 \%)$ and there was no significant difference between trichomoniasis and duration of pregnancy $\left(\mathrm{X}_{2}=0.434, \mathrm{P}>\right.$ $0.05)$. Trichomoniasis was more common in primigravidae $(23.80 \%)$ than in mulitigravidae $(10.13 \%)\left(\mathrm{X}_{2}=5.49, \mathrm{P}<\right.$ $0.05)$. With respect to occupation students were the most affected $(22.22 \%)\left(\mathrm{X}_{2}=10.659, \mathrm{P}>0.05\right)$. The prevalence rate of $13 \%$ obtained in this study is high therefore clinician should routinely screen all pregnant women for the infection.
\end{abstract}

Keywords: Trichomonas vaginalis, Infection, Trichomoniasis, Pregnant, Women, Aba

\section{Introduction}

Trichomoniasis one of the most common sexually transmitted disease is caused by an anaerobic, parasitic, flagellated protozoan called Trichomonas vaginalis. This parasite has an oval or pear shaped appearance but can assume an amoeboid form when attached to vaginal epithelial cell. It has a cosmopolitan distribution and has been identified in both males and females and in all racial and socio-economic groups $(1,2)$. Approximately 180 million people are infected worldwide yearly (3) with the majority living in developing countries (4). The infection is more common in women than in men and older women are more likely to be infected than younger women (5). Higher prevalence is observed among persons with multiple sexual partners or other venereal diseases (1).

The disease is primarily transmitted through sexual contact but contaminated formites such as towels and clothing have been implicated in the transmission (6). Neonatal trichomoniasis can be acquired during passage through an infected birth canal. It is estimated that 2 to $17 \%$ of female babies acquire trichomoniasis through direct vulvo vaginal contamination (7). It has been incriminated as a cofactor in the transmission of HIV (2).

In women the disease typically present as an intense frothy yellow-greenish vaginal discharge, irritation and pain in the vulva, perineum and thighs and dyspareunia and dysuria, but the main clinical manifestation of trichomoniasis is vaginitis, urethritis and prostatitis (8).

Trichomoniasis is reported to be a major cause of pathology in obstetrics and gynecology. The pregnant women infected with this parasite may be at an increased risk of adverse birth outcomes such as premature rupture of membranes, premature labour, low birth weight, neonatal morbidity and mortality, post abortion or poor hysterectomy infection and enhanced predisposition to neoplastic transformation in cervical tissues $(8,9)$.

In Nigeria, trichomoniasis has neither been a focus of study nor are there programmes for prevention and control. In our region there is paucity of information on the epidemiology of trichomoniasis among pregnant women. Hence, this study was undertaken to determine the prevalence of trichomoniasis among pregnant women in Aba.

\section{Subjects and Methods}

\section{Study Population}

A total number of 200 pregnant women who were attending routine antenatal clinic in 2 private clinics and a 
primary health centre in Aba were enrolled for this study. The study was conducted between August to October, 2014. Socio demographic information such as age, pregnancy status and occupation were obtained from the participants by the use of a structured questionnaire. The participants comprised of apparently healthy people without any complicated signs or symptoms of Trichomonas vaginalis infection.

\section{Ethical Consideration}

The management of the three hospitals gave ethical clearance. The approval was on the agreement that patient anonymity must be maintained, good laboratory practice/quality control ensured and that every finding would be treated with utmost confidentiality, informed consent was sought and obtained from participants.

\section{Sample Collection}

Specimens were obtained from the posterior forms of the vagina using sterile swabs and the swab sticks labeled accordingly. Personal identifier initials of the clients only were used in the sample for the purpose of postnatal data. Samples collected were analyzed within one hour of collection. In case of delay, a drop of normal saline was added to the swab stick container and stored in the refrigerator at $4^{\circ} \mathrm{c}$ and assayed within $1-3$ hours.

\section{Laboratory Analysis}

Each sample was poured into a test tube and few drops of normal saline were placed into the tube containing vaginal secretion and centrifuged for 3 minutes at 2000 rotations per minute (rpm) (10). The supernatant was discarded and the sediment examined. Two drops of the sediment was then placed on a clean, grease free slide and was used for wet mount examination.

\section{Statistical Analysis}

Statistical analysis was done using chi-square at $0.05 \%$. A $\mathrm{P}$-value of a less than $0.05(\mathrm{P}<0.05)$ was considered statistically significant.

\section{Results}

Result of the total 200 pregnant women studied, aged $19-$ 42 years revealed that $26(13 \%)$ had Trichomonas vaginalis infection. It was discovered that $T$. vaginalis infection was most prevalent among the $19-26$ years age group comprising $(17.9 \%)$ and lowest within the age group $35-42$ years $(7.1 \%)$ (Table 1$)$.

Women in their third trimester had the highest prevalence of $T$. vaginalis infection (14.6\%) than those in their first trimester (11.1\%) and second trimester (12.5\%) (Table 2).

Prevalence of $T$. vaginalis infection was associated with parity (Table 3 ). With respect to their occupation, the result showed that students had the highest prevalence rate $(22.2 \%)$ followed by house wives $(13.7 \%)$ while civil servants were the least infected $(4.6 \%)$ (Table 4$)$.

Table 1. Prevalence of Trichomonas vaginalis among pregnant women with respect to age group.

\begin{tabular}{cccc}
\hline Age & No Examined & No Positive & Prevalence (\%) \\
\hline $19-26$ & 78 & 14 & $17.95 \%$ \\
$27-34$ & 94 & 10 & $10.64 \%$ \\
$35-42$ & 28 & 2 & $7.14 \%$ \\
\hline Total & 200 & 26 & $13 \%$ \\
\hline
\end{tabular}

Table 2. Prevalence of Trichomonas vaginalis among pregnant women in relation to duration of pregnancy (Trimester).

\begin{tabular}{cccc}
\hline Trimester & No Examined & No Positive & Prevalence (\%) \\
\hline First & 54 & 6 & $11.1 \%$ \\
Second & 65 & 8 & $12.3 \%$ \\
Third & 81 & 12 & $14.8 \%$ \\
\hline Total & 200 & 26 & $13 \%$ \\
\hline
\end{tabular}

Table 3. Prevalence of Trichomonas vaginalis among pregnant women with respect to parity

\begin{tabular}{cccc}
\hline Parity & No Examined & No Positive & Prevalence (\%) \\
\hline Primigravidae & 42 & 10 & $23.80 \%$ \\
Multigravidae & 158 & 16 & $10.13 \%$ \\
\hline Total & 200 & 26 & $13 \%$ \\
\hline
\end{tabular}

Table 4. Prevalence of Trichomonas vaginalis among pregnant women with respect to occupation.

\begin{tabular}{cccc}
\hline Occupation & No Examined & No Positive & Prevalence (\%) \\
\hline Civil Servant & 87 & 4 & $4.59 \%$ \\
Trader & 63 & 12 & $19.05 \%$ \\
Student & 18 & 4 & $22.22 \%$ \\
Housewives & 32 & 6 & $18.75 \%$ \\
\hline Total & 200 & 26 & $13 \%$ \\
\hline
\end{tabular}

\section{Discussion}

Trichomoniasis is of global occurrence and its infection in pregnant women is associated with adverse pregnancy outcomes. In the present study, $13 \%$ of the specimens screened yielded a positive result for $T$. vaginalis among pregnant women. This result is comparable to study conducted by Okonkwo et al. (11) in Abakiliki, Southern Nigerian who reported a prevalence of $12-3 \%$ and Mairiga et al. (8) in Maiduguri, Northern Nigeria who reported a prevalence of $10.99 \%$ but higher than $4.7 \%$ in Ilorin (12), $5.2 \%$ in Calabar (13) and $7.5 \%$ in New Nyanya, Nasarawa (3). Other researchers found a much higher prevalence rate such as $17.7 \%$ in Uyo (14), $18.66 \%$ in Zaria (2). The differences in prevalence could be attributed to sample size, social, cultural and environmental status of the population sampled.

Amongst the different age groups investigated, trichomoniasis was more prevalent in the $19-26$ year age group $(17.95 \%)$, followed by $27-34$ year age group $(10.64 \%)$ which was statistically non-significant. This finding is in agreement with that of Jatau et al. (2), Ali et al. 
(15) and Uneke et al. (9) who stated that these groups of women are sexually active. However, no particular age group was entirely free from the infection.

In this study, women in the third trimester had the highest prevalence of $T$. vaginalis infection (14.8\%) with no significant difference followed by women in the second trimester $(12.3 \%)$. Some studies show that the prevalence is more in the first trimester $(13,16)$, some indicated third trimester had more $(8,9,11,14)$ while some found more in second trimester $(17,18)$. This is worrisome in the third trimester because it could lead to increased adverse birth outcomes and vertical transmission from mother to neonate if not treated on time. However, it is important to screen pregnant women during all the trimesters (8).

With regards to parity, there was a significant difference between trichomoniasis and parity. This is consistent with a report by Opara et al. (14) who obtained a higher prevalence of trichomoniasis among primigravida group of pregnant women. The difference is difficult to explain and may require further investigation in terms of analysis of other related factors.

Students were the most infected in this study $(22.22 \%)$ followed by traders $(19.05 \%)$. The reason for this outcome is somehow obscure but may be attributed to the level of toilet sanitation in schools, halls of residence and in the markets. Lack of awareness of the public health effects of $T$. vaginalis infection could also be a risk factor amongst these groups

\section{Conclusions}

In conclusion, the prevalence of trichomoniasis in this study is $13 \%$ which is a public health problem. Therefore, trichomoniasis should be stressed during antenatal sessions. All pregnant women should be routinely screened for the infection and adequate treatment given to avoid its effects on pregnancy and the fetuses.

\section{REFERENCES}

[1] Iwueze, M. O., Ezeanyanwu, L. N., Okafor, F. C., Nwaorgu, O. C. and Ukibe, S. C. (2014). Prevalence of Trichomonas vaginalis infection among women attending hospitals/health centres in Onitsha Community, Onitsha North Local Government Area of Anambra State. Biosci J., 2 (1): 54 - 64.

[2] Jatau, E. D., Olonitola, O. S. and Olayinka, A. T. (2006). Prevalence of Trichomonas infection among women attending antenatal clinics in Zaria, Nigeria. Annals Afr Med., 5 (4): $178-181$.

[3] Abioye, J. O. K, Ihuma, J. O., Abdullahi, D. K., Awari, Y. S., Gemma, K. and Babatunde, S. K. (2014). Trichomonas vaginalis among pregnant women attending New Nyanya General Hospital, Nasarawa State, Nigeria. IJSN., 5 (3): 437 439.
[4] Adu-Sarkodie, Y. (2004). Trichomonas vaginalis screening global. Sex Trans Infect., 80:201 - 203.

[5] Johnson, V. J. and Mabey, D. C. (2008). Global epidemiology and control of Trichomonas vaginalis. Current Opt Infect Dis., $21(1): 56-64$.

[6] Alcamo, I. E. (2000). Fundamentals of Microbiology - Boston: Jones and Bartlett Publishers, 486 - 487.

[7] Ochei K.C., Obeagu E.I., Ugwu G.U. and George C.N. (2014). Prevalence of Trichomonas vaginalis among pregnant women attending hospital in Irrua specialist teaching hospital in Edo State, Nigeria. IOSR - JOMS., 13 (a):79- 82. O - ISSN: 2279 - 0858, P - ISSN: 2279 - 0861.

[8] Mairiga, A. G., Balla, H. J. and Ahmad, M. I. (2011). Prevalence of Trichomonas vaginalis infections among antenatal clients in Maiduguri, Nigeria. Int. J. Biol Med. Res., 2 (4): $998-1002$.

[9] Uneke C.J., Ugwuoru C.D.C, Ali E and Ali M (2006). Trichomonas vaginalis infection among pregnant women in South Eastern, Nigeria: the public health significance. The Internet J Gyn Obs., 6 (1): 17 - 21.

[10] Centres for Disease Control and Prevention (2006). Sexually transmitted diseases treatment guidelines. MMWR., 55 (11): 1 -94 .

[11] Okonkwo, E. C., Amadi, E. S., Idioha, J. C., Nworie, O., Nwuzo, A. C., and Onwe, .J. C. (2010). Prevalence of Trichomonas vaginalis among pregnant women in Abakiliki, Ebonyi State. Int J. Curr Res., 11:11-15.

[12] Aboyeji, A. P. and Nwabuisi, C. (2003). Prevalence of Sexually transmitted diseases among pregnant women in Ilorin, Nigeria. J. Obstet Gynecol., 23:637 - 639.

[13] Usanga V.U., Abia - Bassey L, Inyanga - Etoh P.C. and Udoh S. (2010). Trichomonas vaginalis infection among pregnant women in Calabar, Cross River State, Nigeria. The Internet $J$ Gyn Obs., 14 (2): 101 - 107.

[14] Opara, K., Udoidiung, N., Atting, T., Bassey, E., Okon, E. and Nwabueze, A. (2009). Risk factors for vaginal trichomoniasis among women in Uyo, Nigeria. The Internet J. Healt., 9 (2): 101-115.

[15] Ali, F. B., Abbas, A., Kazem, B., Mahin, G. and Sayyedehyasmin, N. (2009). Frequency distribution of Trichomoniasis in pregnant women referred to health centres of Ardakan, Meibod and Yazd, Iran. Jundi J. Microbiol., 2 (4): 132- 139 .

[16] Njoku, A. J., Obiajuru, I. O. C., Njoku, C. J., Nwokoro, E. A., Uwaezuoke, J. C. and Anosike, J. C. (2000). Prevalence of Trichomonas vaginalis infection among students of tertiary institutions in Imo State, Nigeria. Nigerian J Parasitol., 21:83 $-94$.

[17] Bakare, R. A., Oni, A. A., Uma, S. A., Fayemiwo, N. A., Fasina, I. F. and Shokunbi, A. (2002). Prevalence of Trichomonas vaginalis amongst commercial sex workers in Ibadan, Nigeria. Afri J Clinic Exptal Microbiol., 4 (2): 25 29.

[18] Mahdi, N. K., Gany, Z. H. and Sharief, M. (2001). Risk factors for vaginal Trichomoniasis among women of Basra, Iraq. East Med Health J., (6):918 - 924. 